Kumawula, Vol. 3, No.3, Desember 2020, Hal 465 - 468 DOI: https://doi.org/10.24198/kumawula.v3i3.28626

ISSN 2620-844X (online)

Tersedia online di http://jurnal.unpad.ac.id/kumawula/index

\title{
KEGIATAN PEMBERIAN BANTUAN SOSIAL PANDEMI COVID-19 DI DESA SEKITAR KAMPUS UNPAD JATINANGOR
}

\author{
Wahyu Gunawan ${ }^{1}$, Dianne Amor Kusuma ${ }^{2 *}$ \\ ${ }^{1}$ Departemen Sosiologi FISIP Universitas Padjadjaran \\ ${ }^{2}$ Departemen Matematika FMIPA Universitas Padjadjaran \\ *Korespondensi : amor@unpad.ac.id
}

\begin{abstract}
ABSTRAK
Pandemi Covid-19 sangat berdampak terhadap kondisi ekonomi masyarakat. Tujuan dilaksanakannya kegiatan pemberian bantuan sosial pandemi Covid-19 ini adalah sebagai wujud empati serta kepedulian beberapa dosen Universitas Padjadjaran (Unpad) terhadap masyarakat terdampak Covid-19. Fokus dalam kegiatan ini adalah membantu masyarakat di beberapa desa sekitar kampus Unpad Jatinangor yang kekurangan bahan pangan. Hasil survei dan pendataan yang dilakukan, tercatat beberapa desa yang sangat membutuhkan bahan pangan disebabkan sebagian besar masyarakatnya kehilangan mata pencaharian akibat pandemi Covid-19. Oleh karena itu perlu dilakukan upaya yang dapat meringankan beban mereka. Metode yang dilakukan dalam upaya membantu meringankan beban masyarakat adalah dengan cara melaksanakan kegiatan pemberian bantuan sosial di desa-desa sekitar kampus Unpad Jatinangor yang berbentuk bahan makanan. Hasil dari kegiatan ini adalah tanggapan positif dari masyarakat karena mereka sangat terbantu dengan adanya kegiatan ini dan sangat berharap agar kegiatan ini dilakukan secara berkelanjutan dan lebih merata.
\end{abstract}

Kata kunci: Dampak Covid-19, kondisi ekonomi, bantuan sosial.

\section{THE ACTIVITY OF COVID-19 PANDEMIC SOCIAL ASSISTANCE IN THE VILLAGES AROUND UNPAD CAMPUS}

\begin{abstract}
The Covid-19 Pandemic has had a huge impact on the economic conditions of the community. The purpose of carrying out the activity of providing social assistance during the Covid-19 Pandemic is a form of empathy and concern for some Universitas Padjadjaran (Unpad) lecturers for the people affected by Covid-19. The focus of this activity is to help people in several villages around the Jatinangor Unpad campus who are short on food. The results of the survey and data collection showed that several villages were in dire need of food because most of the people had lost their livelihoods due to the Covid-19 Pandemic. Therefore, it is necessary to make efforts to ease their burden. The method used in an effort to help ease the burden on the community is by carrying out social assistance activities in the villages around the Jatinangor Unpad campus in the form of foodstuffs. The result of this activity is a positive response from the community because they are greatly helped by this activity and really hope that this activity is carried out in a more sustainable and equitable way.
\end{abstract}

Keyword : The impact of Covid-19; economic conditions, social assistance.

\section{PENDAHULUAN}

Saat ini hampir seluruh penduduk di dunia sedang dihadapkan pada musibah yang sangat besar dan memakan banyak korban, yakni pandemi Covid-19 yang belum berhasil ditemukan obat ataupun vaksinnya. Tak terkecuali di Indonesia. Pandemi ini tidak hanya berdampak pada sangat banyaknya korban yang berjatuhan hari demi hari, namun juga berdampak pada segala aspek kehidupan, salah satunya adalah aspek ekonomi (Budastra, 2020). Dengan diberlakukannya lockdown di beberapa daerah dan aturan social distancing, sedikit banyak berdampak pada menurunnya penghasilan penduduk Indonesia terutama pada 
masyarakat di pedesaan. Karena menurunnya penghasilan, maka sebagian besar masyarakat merasa kesulitan dalam memenuhi kebutuhan sehari-hari. Hal ini dirasakan pula oleh masyarakat di desa-desa sekitar kampus Unpad Jatinangor. Sebagai makhluk sosial, kita sebagai manusia tidak dapat hanya berpangku tangan melihat kondisi ini. Perlu dilakukan upaya untuk mengatasinya. Banyak cara yang dapat dilakukan untuk mengatasi kondisi tersebut, salah satunya adalah bentuk pemberian bantuan sosial. Bantuan sosial adalah barang yang digunakan untuk membantu masyarakat yang membutuhkan (Asmaroini, 2012).

Berdasarkan hasil wawancara dengan para aparat desa yang dilakukan pada tanggal 15-16 April 2020, diperoleh informasi bahwa sebagian masyarakat di desa-desa sekitar kampus Unpad Jatinangor kehilangan pekerjaan sebagai dampak pandemi Covid-19, sehingga mereka merasa kesulitan dalam memenuhi kebutuhan sehari-hari terutama bahan pangan. Untuk itu 34 orang dosen Unpad berinisiatif untuk melakukan kegiatan pemberian bantuan sosial pandemi Covid-19 dalam upaya turut meringankan beban masyarakat di desa-desa sekitar kampus Unpad Jatinangor. Kegiatan yang dilakukan berupa pemberian bantuan bahan pangan. Adapun desa-desa yang menjadi lokasi kegiatan ini adalah: Cikeruh, Cibeusi, Sayang, Hegarmanah, Cisempur, Cipacing, Jatiroke, Jatimukti, Cilayung, Mekargalih, Cinta Mulya, dan Cileles.

\section{METODE}

Kegiatan pemberian bantuan sosial pandemi Covid-19 yang dilaksanakan di desadesa sekitar kampus Unpad Jatinangor ini sebagai upaya untuk membantu meringankan beban masyarakat. Sasaran dalam kegiatan ini adalah masyarakat desa Cikeruh, Cibeusi, Sayang, Hegarmanah, Cisempur, Cipacing, Jatiroke, Jatimukti, Cilayung, Mekargalih, Cinta Mulya, dan Cileles. Kegiatan ini dilakukan melalui beberapa tahapan, yakni tahap persiapan, pelaksanaan, dan evaluasi. Tahap persiapan meliputi: 1) Menerapkan metode survei, yang bertujuan untuk mengetahui lokasi mana saja yang sangat memerlukan bantuan; 2) Mengindentifikasi kebutuhan paling mendesak yang diperlukan masyarakat; 3) Menunjuk beberapa koordinator lapangan dari beberapa desa yang dituju, agar memudahkan dalam penerimaan dan pendistribusian bantuan; dan 4) Menentukan jadwal pendistribusian bantuan. Tahap pelaksanaan meliputi: a) Menyiapkan bantuan; b) Menentukan titik temu untuk serah terima bantuan; c) Berkoordinasi dengan para koordinator lapangan untuk pendistribusian bantuan; dan d) Menyerahkan bantuan pada masyarakat melalui para koordinator lapangan. Berikutnya, tahap evaluasi yang dilakukan untuk mengetahui sejauh mana bantuan yang diberikan dapat membantu meringankan masyarakat di desa-desa sekitar kampus Unpad Jatinangor yang terdampak Covid-19.

\section{HASIL DAN PEMBAHASAN}

Covid-19 telah menyebar hingga ke seluruh penjuru dunia, termasuk Indonesia, dan sangat berdampak pada sektor perekonomian. Pandemi Covid-19 pun berdampak pada sektor perdagangan, usaha mikro, kecil, dan menengah (Hanoatubun, 2020). Banyak UMKM yang berjalan dengan modal, SDM, serta kemampuan bisnis yang terbatas terpaksa harus gulung tikar di tengah pandemi ini (Sugiarti, Sari, \& Hadiyat, 2020). Dampak pada sektor-sektor tersebut tidak hanya dirasakan oleh masyarakat yang tinggal di kota-kota besar, namun dirasakan juga oleh masyarakat yang tinggal di pedesaan, seperti halnya masyarakat di desa-desa sekitar kampus Unpad Jatinangor. Selama masa pandemi Covid19, tak sedikit masyarakat di desa-desa tersebut yang kehilangan pekerjaan dan sumber mata pencaharian sehingga berdampak pada sulitnya memenuhi kebutuhan sehari-hari. Sebagian besar masyarakat yang tinggal di desa-desa sekitar kampus Unpad Jatinangor bekerja sebagai buruh harian lepas, buruh tani, karyawan perusahaan swasta, petani, pengusaha kecil dan menengah (Kusuma, 2019).

Hampir sebagian besar desa-desa di sekitar kampus Unpad Jatinangor sudah 
mengalami pembangunan, dalam arti beberapa lahan pertanian sudah dijadikan bangunan yang kemudian difungsikan sebagai rumah sewa mahasiswa (rumah kos mahasiswa) ataupun tempat untuk berniaga, seperti jasa laundry, cafetaria, dan beberapa tempat jajanan. Pandemi ini menyebabkan tempat-tempat tersebut menjadi sepi dikarenakan sebagian besar mahasiswa sudah kembali ke kampung halaman masing-masing dan melanjutkan perkuliahan secara daring. Selain itu, sebagian masyarakat yang bekerja sebagai karyawan perusahaan swasta pun "dirumahkan" akibat pandemi ini. Dan karena sebagian lahan pertanian telah beralih fungsi, maka jumlah masyarakat yang bekerja di sektor pertanian pun berkurang (Mukti, et. al., 2018) dan otomatis mengurangi kapasitas penyediaan bahan pangan (Kaputra, 2013), sehingga masyarakat di desa-desa sekitar kampus Unpad Jatinangor kesulitan dalam memperoleh bahan pangan pada masa pandemi ini. Kondisi tersebut menggugah nurani beberapa dosen Unpad untuk membantu meringankan beban mereka dengan cara mengadakan kegiatan pemberian bantuan sosial berbentuk bahan makanan.

\section{Tahap Persiapan Kegiatan}

Sebelum kegiatan ini dilakukan, dilakukan wawancara terhadap para aparat desa sekitar kampus Unpad Jatinangor selama dua hari untuk mengidentifikasi lokasi mana saja yang sangat memerlukan bantuan, serta untuk mengetahui apa yang paling dibutuhkan oleh masyarakat. Setelah itu, ditunjuk beberapa koordinator lapangan yang mewakili desa-desa yang akan dibantu guna memudahkan pendistribusian bantuan. Selanjutnya beberapa dosen mengumpulkan, mengemas, dan menyiapkan bahan bantuan mulai tanggal 17 April hingga 21 April 2020, serta berkoordinasi dengan para koordinator lapangan untuk menentukan jadwal pendistribusian bantuan.

\section{Tahap Pelaksanaan Kegiatan}

Setelah bahan bantuan selesai dikemas dan disiapkan, beberapa dosen berkoordinasi dengan para koordinator lapangan untuk menentukan titik temu penyerahan bantuan yang akan didistribusikan kepada masyarakat di desa-desa sekitar kampus Unpad Jatinangor. Pada tanggal 22 April 2020, kegiatan pemberian bantuan sosial pandemi Covid-19 ini dilaksanakan, yakni penyerahan bantuan kepada masyarakat di desadesa sekitar kampus Unpad Jatinangor yang terdampak pandemi Covid-19. Kegiatan ini melibatkan 34 orang dosen Unpad dari beberapa fakultas.

Berdasarkan hasil survei yang telah dilakukan, diperoleh data bahwa yang paling dibutuhkan masyarakat di desa-desa sekitar kampus Unpad Jatinangor di masa pandemi Covid-19 adalah bahan makanan. Adapun desadesa yang menjadi lokasi kegiatan ini adalah sebagai berikut:

1. Desa Cikeruh RW 05 dan RW 09

2. Desa Cibeusi RW 03

3. Desa Sayang RW 07, RW 09, RW 12, dan RW13

4. Desa Hegarmanah RW 01 dan RW 07

5. Desa Cisempur RW 05

6. Desa Cipacing RW 01, RW 03, RW 05, RW 09, dan RW 10

7. Desa Jatiroke RW 01

8. Desa Jatimukti RW 02, RW 04, dan RW 05

9. Desa Cilayung RW 02, RW 04, dan RW 08

10. Desa Mekargalih RW 04

11. Desa Cinta Mulya RW 04

12. Desa Cileles RW 08.

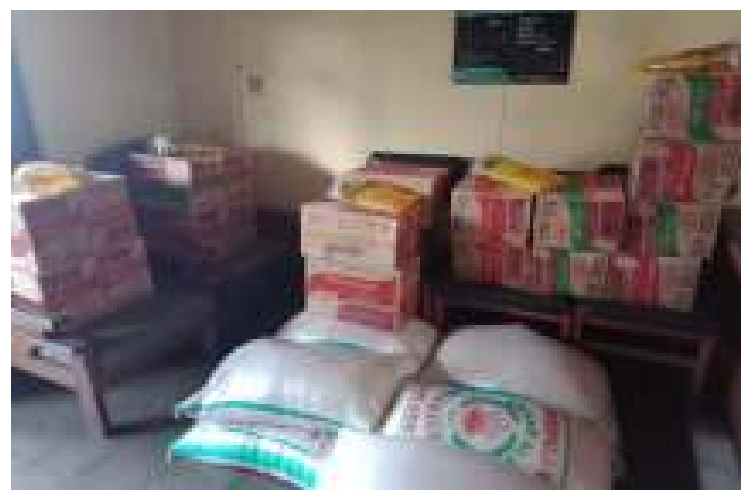

Gambar 1 Bahan Makanan yang Didistribusikan kepada Masyarakat 


\section{Tahap Evaluasi Kegiatan}

Setelah seluruh bantuan didistribusikan kepada masyarakat desa-desa sekitar kampus Unpad Jatinangor yang terdampak Covid-19, dilakukan evaluasi kegiatan yang meliputi pengumpulan informasi terkait dari para koordinator lapangan mengenai sejauhmana bantuan yang diberikan dapat meringankan beban masyarakat. Berdasarkan informasi yang diberikan para koordinator lapangan, diketahui bahwa masyarakat di desa-desa sekitar kampus Unpad Jatinangor sangat terbantu dengan adanya kegiatan pemberian bantuan sosial yang dilakukan oleh 34 orang dosen Unpad dari beberapa fakultas.

\section{SIMPULAN}

Pandemi Covid-19 berdampak buruk pada segala lapisan masyarakat. Tidak hanya masyarakat yang tinggal di kota-kota besar, namun masyarakat di pedesaan pun turut merasakan dampaknya. Kondisi ini dirasakan pula oleh masyarakat yang tinggal di desa-desa sekitar kampus Unpad Jatinangor. Selama masa pandemi Covid-19 ini, sebagian besar masyarakat di desa-desa sekitar kampus Unpad Jatinangor merasa kesulitan dalam memenuhi kebutuhan sehari-hari, terutama bahan makanan.

Oleh karena itu, sasaran kegiatan ini adalah memberikan bantuan kepada masyarakat terdampak Covid-19 di desa-desa sekitar kampus Unpad Jatinangor guna meringankan beban mereka. Dengan diadakannya kegiatan ini diharapkan masalah yang dihadapi masyarakat di desa-desa sekitar kampus Unpad Jatinangor dalam memenuhi kebutuhan bahan makanan dapat sedikit teratasi. Dan agar kegiatan ini tetap terjaga keberlanjutannya, sebaiknya kegiatan pemberian bantuan sosial juga dilakukan di lokasi-lokasi lain sekitar kampus Unpad Jatinangor.

\section{UCAPAN TERIMA KASIH}

Paper ini merupakan hasil Pengabdian kepada Masyarakat dalam kegiatan pemberian bantuan sosial pandemi Covid-19. Ucapan terima kasih disampaikan kepada Rektor Universitas Padjadjaran, Direktorat Riset,
Pengabdian kepada Masyarakat dan Inovasi, serta para Ketua RW di Desa Cikeruh, Cibeusi, Sayang, Hegarmanah, Cisempur, Cipacing, Jatiroke, Jatimukti, Cilayung, Mekargalih, Cinta Mulya, dan Cileles.

\section{DAFTAR PUSTAKA}

Asmaroini, A. P. (2012). Efektivitas Bantuan Sosial bagi Masyarakat Kampung Idiot di Desa Karangpatihan Kecamatan Balong Kabupaten Ponorogo. Skripsi, Universitas Negeri Malang, Tidak Diterbitkan.

Budastra, I. K. (2020). Dampak Sosial Ekonomi Covid-19 dan Program Potensial untuk Penanganannya: Studi Kasus di Kabupaten Lombok Barat. Jurnal Agrimansion, 21(1): 48-57.

Hanoatubun, S. (2020). Dampak Covid-19 terhadap Perekonomian Indonesia. Journal of Education, Psychology and Counseling, 2(1): 146-153.

Kaputra, I. (2013). Alih Fungsi Lahan, Pembangunan Pertanian dan Kedaulatan Pangan. Jurnal Strukturalisasi, 1(1): 2539.

Kusuma, D. A. (2019). Pemanfaatan Limbah Plastik untuk Pembuatan Paving Block di Desa Cileunyi Kulon. Kumawula: Jurnal Pengabdian kepada Masyarakat Unpad, 2(3): 211-217.

Mukti, G. W., Sadeli, A. H., \& Kusno, K. (2018). Penguatan Kapasitas Kewirausahaan Petani Muda Hortikultura Skala Kecil di Kecamatan Parongpong Kabupaten Bandung Barat. Kumawula: Jurnal Pengabdian kepada Masyarakat Unpad, 1(1): 50-61.

Sugiarti, Y., Sari, Y., \& Hadiyat, M. A. (2020). Peranan E-Commerce untuk Meningkatkan Daya Saing Usaha Mikro Kecil dan Menengah (UMKM) Sambal di Jawa Timur. Jurnal Kumawula: Jurnal Pengabdian Kepada Masyarakat, 3(2), 298-309.

https://doi.org/https://doi.org/10/24198/k umawula.v3i2.28181 